\title{
Cytochrome c oxidase contains an extra charged amino acid cluster in a new type of respiratory chain in the amino-acid-producing Gram-positive bacterium Corynebacterium glutamicum
}

\author{
Junshi Sakamoto, ${ }^{1}$ Takatsugu Shibata, ${ }^{1}$ Tadashi Mine, ${ }^{1}$ Ryoko Miyahara, ${ }^{1}$ \\ Tomokimi Torigoe, ${ }^{1}$ Shunsuke Noguchi, ${ }^{1}$ Kazunobu Matsushita ${ }^{2}$ \\ and Nobuhito Sone ${ }^{1}$
}

1 Department of Biochemical Engineering and Science, Kyushu Institute of Technology, Kawazu 680-4, lizuka, Fukuoka-ken 820-8502, Japan

2 Department of Biological Chemistry, Faculty of Agriculture, Yamaguchi University, Yamaguchi, Yamaguchi 753-0841, Japan
Author for correspondence: Junshi Sakamoto. Tel: +81948 297823. Fax: + 81948297801. e-mail: sakamoto@bse.kyutech.ac.jp

The membranes from Corynebacterium glutamicum cells contain a hydrophobic di-haem C protein as the cytochrome $c$ subunit of the new type of cytochrome bc complex (complex III in the respiratory chain) encoded by the qcrCAB operon [Sone, N., Nagata, K., Kojima, H., Tajima, J., Kodera, Y., Kanamaru, T., Noguchi, S. \& Sakamoto, J. (2001). Biochim Biophys Acta 1503, 279-290]. To characterize complex IV, cytochrome $c$ oxidase and its structural genes were isolated. The oxidase is of the cytochrome $\mathrm{aa}_{3}$ type, but mass spectrometry indicated that the haem is haem As, which contains a geranylgeranyl sidechain instead of a farnesyl group. The enzyme is a SoxM-type haem-copper oxidase composed of three subunits. Edman degradation and mass spectrometry suggested that the $\mathbf{N}$-terminal signal sequence of subunit II is cleaved and that the new $\mathbf{N}$-terminal cysteine residue is diacylglycerated, while neither subunit I nor subunit III is significantly modified. The genes for subunits II (ctaC) and III (ctaE) are located upstream of the qcrCAB operon, while that for subunit I (ctaD) is located separately. The oxidase showed low enzyme activity with extrinsic substrates such as cytochromes $c$ from horse heart or yeast, and has the $\mathrm{Cu}_{\mathrm{A}}$-binding motif in its subunit II. A prominent structural feature is the insertion of an extra charged amino acid cluster between the $\beta 2$ and $\beta 4$ strands in the substrate-binding domain of subunit II. The $\beta 2-\beta 4$ loop of this oxidase is about 30 residues longer than that of major cytochrome $c$ oxidases from mitochondria and proteobacteria, and is rich in both acidic and basic residues. These findings suggest that the extra charged cluster may play a role in the interaction of the oxidase with the cytochrome $c$ subunit of the new type of bc complex.

Keywords: cytochrome $a a_{3}$, dihaem cytochrome $c$, glutamate fermentation, high-G $+\mathrm{C}$ Gram-positive bacteria

\section{INTRODUCTION}

Cytochrome $c$ is a peripheral membrane protein located in the periplasmic space of bacteria as well as in the

Abbreviations: DG, $n$-decyl-D-glucoside; MALDI, matrix-assisted laser desorption ionization; MEGA 9, $n$-nonanoyl $N$-metylglucamide; MEGA 10 , $n$-decanoyl $N$-methylglucamide; PTH, phenylthiohydantoin; TMPD, $N, N, N^{\prime}, N^{\prime}$-tetramethyl-p-phenylenediamine.

The GenBank/EMBL/DDBJ accession numbers for the sequences reported in this paper are $A B 052748$ and $A B 052749$. mitochondrial intermembrane space of eukaryotes, which transfers electrons from the cytochrome $b c_{1}$ complex (complex III) to cytochrome $c$ oxidase (complex IV) in the respiratory chain. Gram-positive bacteria have no outer membrane or periplasmic space and contain four types of cytochrome $c$ with a membrane anchor. Cytochrome $c-551$ in the thermophilic Bacillus species is bound to the cell membrane by a diacylglycerol moiety covalently linked to the $\mathrm{N}$-terminal cysteine residue (Noguchi et al., 1994), whereas cytochrome 
c-550 in Bacillus subtilis is bound to the membrane by its N-terminal hydrophobic signal peptide (von Wachenfeldt \& Hederstedt, 1993). The third type, cytochrome $\mathrm{Caa}_{3}$-type oxidase, contains a cytochrome $c$ moiety genetically fused to the C-terminus of subunit II and accepts electrons directly from the cytochrome $b c$ complex in the absence of another cytochrome $c$ (Sone et al., 1987). Finally, we have recently identified a new type of cytochrome $c$ which is genetically fused to the cytochrome $c$ subunit of the cytochrome $b c$ complex from Corynebacterium glutamicum (Sone et al., 2001). C. glutamicum is an aerobic high-G + C Gram-positive bacterium of industrial importance in the production of amino acids used as nutritious additives in food and fodder. Electrophoretic analysis indicated that the organism has only one $c$-type cytochrome and the purified cytochrome contains two moles haem C per mole polypeptide (Sone et al., 2001). The gene $q \mathrm{cr} C$ sequence indicates that the subunit consists of two type-I cytochrome $c$ domains with two haem C-binding motifs, $\mathrm{CXXCHX}_{\mathrm{n}} \mathrm{M}$; thus, we named it 'cytochrome $c c$ '. This gene and two others constitute a $q c r C A B$ operon encoding a putative cytochrome $b c$ complex. Similar $q c r C A B$ operons are present in the genomes of other high-G + C Gram-positive bacteria, such as Mycobacterium tuberculosis (Cole et al., 1998).

These findings prompted us to study the structural features of cytochrome $c$ oxidase in this organism. Cytochrome $b d$-type oxidase and its structural genes have been isolated previously from C. glutamicum (Kusumoto et al., 2000), and it has been determined that the enzyme is a menaquinol oxidase operating via an alternative electron-transfer pathway, as in other bacteria. In this work, we have isolated a cytochrome $a a_{3}$ type cytochrome $c$ oxidase and have cloned its structural genes. In comparison with other cytochrome $c$ oxidases, the enzyme has a long insertion containing both basic and acidic amino acid residues in the cytochrome $c$ binding domain of subunit II.

\section{METHODS}

Cell growth and membrane preparation. The cells of $C$. glutamicum KY9002 (ATCC 13032) were grown aerobically at $30{ }^{\circ} \mathrm{C}$ as described previously (Kusumoto et al., 2000). Cells were harvested at the early stationary phase by centrifugation at $8000 \mathrm{~g}$ for $15 \mathrm{~min}$ and stored in a freezer. Cells of about $120 \mathrm{~g}$ wet weight were suspended in $200 \mathrm{ml} 10 \mathrm{mM} \mathrm{NaP}{ }_{i}$ buffer $(\mathrm{pH} 7 \cdot 4)$ containing $0.5 \% \quad(\mathrm{w} / \mathrm{v}) \mathrm{NaCl}$ and were disrupted by vigorous mixing with glass beads (diameter $0.5 \mathrm{~mm}, 350 \mathrm{~g}$ ) in a cell-disrupting mixer Bead-Beater (Biospec) for $2 \mathrm{~min}$, five times in ice water. Unbroken cells were removed by centrifugation at $8000 \mathrm{~g}$ for $10 \mathrm{~min}$ and then the supernatant was centrifuged at $100000 \mathrm{~g}$ for $60 \mathrm{~min}$. The precipitate was resuspended in a buffer containing $100 \mathrm{mM}$ $\mathrm{NaCl}$ and $50 \mathrm{mM} \mathrm{KP}_{\mathrm{i}}$ at $\mathrm{pH} 6.5$ and used as the membranes.

Enzyme preparation. The membranes were suspended at 5 or $10 \mathrm{mg}$ protein $\mathrm{ml}^{-1}$ in a buffer containing $2 \%(\mathrm{w} / \mathrm{v})$ sodium cholate, $0.5 \mathrm{M} \mathrm{NaCl}$ and $10 \mathrm{mM} \mathrm{NaP}_{\mathrm{i}}$ at $\mathrm{pH} 7 \cdot 4$, then sonicated for $2 \mathrm{~min}$ (five times). The membrane proteins sedimented at $100000 \mathrm{~g}$ for $30 \mathrm{~min}$ were resuspended in a buffer containing $2 \%(\mathrm{w} / \mathrm{v}) n$-decyl-D-glucoside (DG), $0.5 \mathrm{M}$
$\mathrm{NaCl}, 50 \mathrm{mM} \mathrm{KP}$, $\mathrm{pH} 6 \cdot 5$, then sonicated and centrifuged as described above. The extract was dialysed against $10 \mathrm{mM}$ $\mathrm{NaP}_{\mathrm{i}}(\mathrm{pH} 7 \cdot 4)$ and applied to a DEAE-Toyopearl column $(1.4 \times 10 \mathrm{~cm})$. Absorbed proteins were eluted with a buffer containing $1 \%$ DG, $10 \mathrm{mM} \mathrm{NaP}{ }_{\mathrm{i}}(\mathrm{pH} 7 \cdot 4)$ and increasing concentrations of $\mathrm{NaCl}$. The peak fractions of cytochrome $a a_{3}$ at $200 \mathrm{mM} \mathrm{NaCl}$ were applied to a hydroxyapatite column $(0 \cdot 8 \times 2 \mathrm{~cm})$, then proteins were eluted with a $1 \%$ DG solution containing increasing concentrations of $\mathrm{NaP}_{\mathrm{i}}$ buffer. The cytochrome was mainly recovered at $200 \mathrm{mM} \mathrm{NaP}$.

Enzymic activity. $N, N, N^{\prime}, N^{\prime}$-Tetramethyl-p-phenylenediamine (TMPD) oxidase activity was measured at $25^{\circ} \mathrm{C}$ in the presence of $250 \mu \mathrm{M}$ TMPD, $0 \cdot 1 \mathrm{M} \mathrm{NaCl}, 1 \mathrm{mM}$ EDTA and $50 \mathrm{mM} \mathrm{NaP}_{\mathrm{i}}$ buffer at $\mathrm{pH} 6.5$ by monitoring the increase in the $A_{562}$ value, and was calculated by using a millimolar absorption coefficient $\left(\varepsilon_{562}\right)$ of $10.5 \mathrm{mM}^{-1} \mathrm{~cm}^{-1}$ (Sakamoto et al., 1996). For cytochrome $c$ oxidase activity, yeast or horseheart cytochrome $c$ was reduced with hydrosulfite and separated by a centrifuged column containing Sephadex G-50 (fine). The reaction was started by mixing cytochrome $c$ with cytochrome $a a_{3}$ at final concentrations of $0.1 \mathrm{mM}$ and $0.5 \mu \mathrm{M}$, respectively, in $20 \mathrm{mM} \mathrm{NaP}_{\mathrm{i}}$ ( $\left.\mathrm{pH} 7 \cdot 4\right)$. The amount of residual ferrocytochrome $c$ was calculated from absorption spectra using a millimolar absorption coefficient $\left(\varepsilon_{550}\right)$ of $19 \cdot 1 \mathrm{mM}^{-1} \mathrm{~cm}^{-1}$. The oxidase activity of the membranes was measured using a Yellow Springs oxygen electrode (no. 4005) at $30^{\circ} \mathrm{C}$ in a $2.3 \mathrm{ml}$ semi-closed vessel containing a respiratory substrate in $20 \mathrm{mM} \mathrm{KP}$ buffer at $\mathrm{pH} 6.5$, as described previously (Sakamoto et al., 1997).

Cloning of the genes. Gene manipulations were carried out as described previously (Sakamoto et al., 1999). To clone the gene for subunit II, a sense primer for PCR, 5'-GGYGAYTTCYTBCGNATGGG-3' (crg1), and an antisense primer, $5^{\prime}-$ GGACCGCASARYTCNGMRCA-3' (crg2r), were designed on the basis of the N-terminal peptide sequence (GDFLRMG) and the highly conserved sequence of the $\mathrm{Cu}_{\mathrm{A}}$-ligating motif (C(A/S)ELCGP-), respectively. A PCR was performed using C. glutamicum chromosomal DNA as the template, and the resultant $0.8 \mathrm{~kb}$ product (AA1) was used as the probe. Chromosomal DNA was partially digested with Sau3AI, and the resultant fragments were ligated to BamHI-digested pUC119. A positive clone (AA41) was obtained by colony hybridization; then, using this as the probe, two other clones (AA51 and AA61) were obtained. These clones contained whole $c t a C$ and ctaE genes, which encode subunits II and III, but did not contain the gene for subunit I. To clone this gene, a set of PCR primers were prepared on the basis of the highly conserved sequences of subunit I of cytochrome $c$ oxidases. A sense primer, 5'-TCATGGTNTGGGYNCAYCAY-3' (uni1), was designed on the basis of a sequence (FMVW(A/V)HH-) between the seventh and eighth transmembrane segments and an antisense primer, 5'-ATAACRTWRTGRAARTGNGC-3' (uni2r), was based on a sequence within the 10th segment (AHFH(Y/N)VI-). A fragment of about $0.3 \mathrm{~kb}$ (AA2) was solely produced and then used as a probe for Southern and colony hybridization to obtain a positive Pst I fragment (AA22) and a SphI fragment (AA32), which make up the whole $c t a D$ gene encoding subunit I.

Other analyses. Absorption spectra were recorded at room temperature, as described previously (Kusumoto et al., 2000). The cytochrome $a a_{3}$ content was calculated from redox difference spectra by using a millimolar absorption coefficient $\left(\varepsilon_{600}\right)$ of $21 \cdot 0 \mathrm{mM}^{-1} \mathrm{~cm}^{-1}$ (Sone \& Yanagita, 1982). To estimate the molecular masses of haems, they were extracted with $\mathrm{HCl} /$ acetone, dried as described previously (Sakamoto et al., 
1997), dissolved in aqueous $30 \%$ acetonitrile solution, and then mixed at a $1: 1$ ratio with a $50 \%$ acetonitrile solution of $10 \mathrm{mg} \alpha$-cyano-4-hydroxycinnamic acid $\mathrm{ml}^{-1}$ and $0 \cdot 1 \%$ trifluoroacetic acid. The mixture was spotted onto a sample plate and analysed using a matrix-assisted laser desorption ionization (MALDI) mass spectrometer (Voyager LN-DE; PerSeptive Biosystems). MALDI mass spectrometry of proteins was performed using 2-(4-hydroxyphenylazo)benzoic acid as the matrix, as described by Ghaim et al. (1997). Reverse-phase chromatography of haems, the protein concentration assay, SDS-PAGE, and peptide sequence analysis were performed as described previously (Sakmoto et al., 1997, 1999).

Materials. Cytochromes $c$ from bovine heart and yeast were purchased from Sigma. DEAE-Toyopearl, Sephadex G-50 fine, 2-(4-hydroxyphenylazo) benzoic acid and hydroxylapatite were purchased from Tosoh, Pharmacia, Aldrich and Bio-Rad, respectively. MEGA 9, MEGA 10 and $n$-dodecyl $\beta$-Dmaltoside were obtained from Dojin. Other reagents were of analytical grade.

\section{RESULTS}

\section{Purification of cytochrome $\mathrm{aa}_{3}$-type oxidase}

Cells of C. glutamicum were harvested in the early stationary growth phase at an $\mathrm{OD}_{650}$ value of about 14 . The redox difference spectrum of the cell membranes showed the presence of $a$-, $b$ - and $c$-type cytochromes (Fig. 1a, inset). The presence of the a-type cytochrome suggests that the main respiratory oxidase is cytochrome $a a_{3}$. The oxidase activity in the membrane preparations in the presence of $0.2 \mathrm{mM} \mathrm{NADH}$ and TMPD as the respiratory substrate was 560 and 120 ngatomO $\mathrm{min}^{-1}$ (mg protein $)^{-1}$, respectively. The activity was as low as 12 and $10 \mathrm{ng}$-atomO $\mathrm{min}^{-1}(\mathrm{mg} \text { protein })^{-1}$ with $10 \mu \mathrm{M}$ yeast and horse-heart cytochromes $c$ as the substrates, respectively. The solubility of the oxidase was tested in the following detergents: sodium cholate, Triton X-100, sucrose monolaurate, DG, n-dodecyl $\beta$-D-maltoside, and a 1:1 mixture of $n$-nonanoyl $N$ methylglucamide and $n$-decanoyl $N$-methylglucamide (MEGA 9+ MEGA 10). Sodium cholate was ineffective at solubilizing the $a$-type cytochrome but was effective at removing the peripheral proteins. About the same amount of enzyme activity was retained immediately after solubilization in Triton X-100, DG, $n$-dodecyl $\beta$-Dmaltoside, and MEGA $9+$ MEGA 10, and the highest activity remaining $3 \mathrm{~d}$ later was in DG and in $n$-dodecyl $\beta$-D-maltoside. DG was chosen as the detergent for solubilizing the oxidase for ease of availability. This enzyme stability in DG was not affected by the presence of either $15 \%$ glycerol, $1 \%$ asolectin or a combination of peptidase inhibitors ( $1 \mathrm{mM}$ benzamidine hydrochloride, $0.2 \mathrm{mM}$ PMSF and $1 \mathrm{mM}$ EDTA) (data not shown). After solubilization with DG, the proteins were fractionated by DEAE-Toyopearl anionexchange chromatography and then by hydroxyapatite chromatography (Table 1). The turnover number for TMPD oxidase activity dropped about 10 -fold with solubilization. The isolated cytochrome catalysed the oxidation of TMPD, horse-heart cytochrome $c$ and yeast cytochrome $c$, with turnover numbers of $0.61,0.23$ and $2.54 \mathrm{~s}^{-1}$, respectively, indicating that the $a$-type cytochrome is a cytochrome $c$ oxidase, though these values are much lower than those of other cytochrome $c$ oxidases. The activity was not enhanced by the addition of phospholipid extracted from the cells. The cytochrome did not catalyse the oxidation of menaquinol-1, $-2,-3$, dimethylnaphthoquinol, menadiol, ubiquinol-1 or ubiquinol-2 (data not shown), in contrast to the cytochrome $b d$-type quinol oxidase recently isolated from this organism (Kusumoto et al. 2000). In addition, it did not catalyse the oxidation of azurin from Pseudomonas aeruginosa.
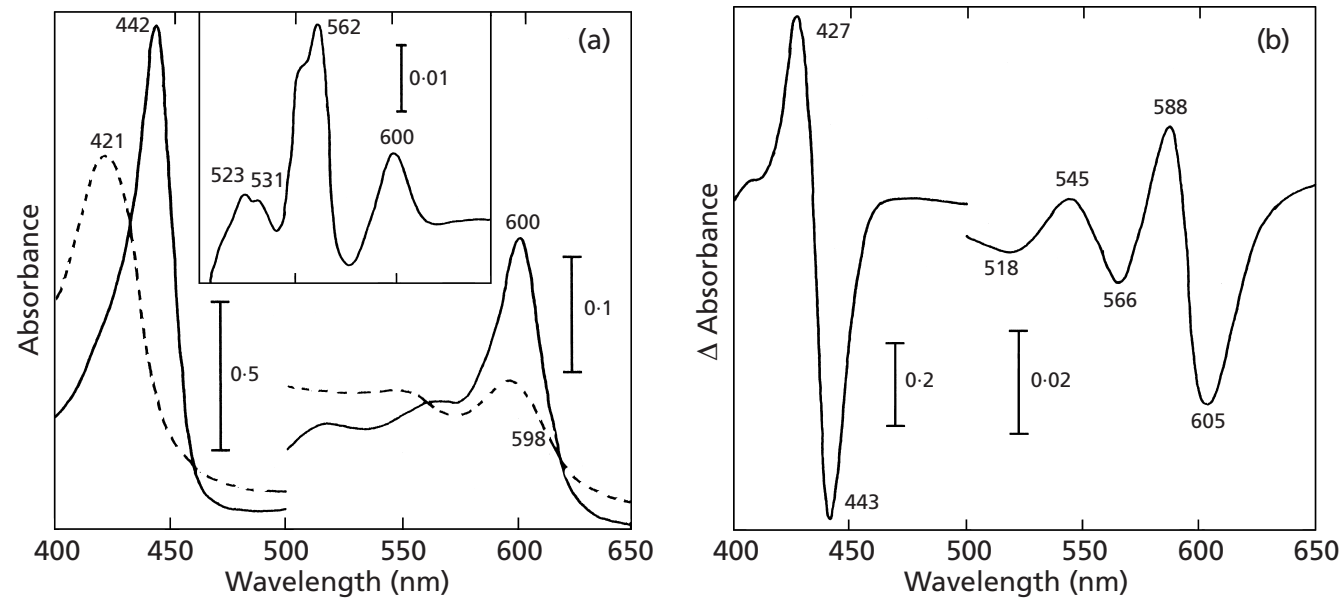

Fig. 1. Absorption spectra of cytochrome aa $a_{3}$-type oxidase. (a) Absolute spectra are shown for the air-oxidized (broken

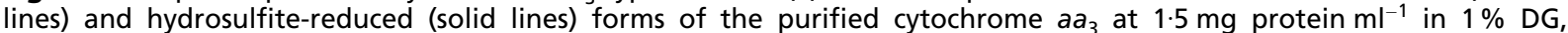
$200 \mathrm{mM} \mathrm{NaP}$ ( $\mathrm{pH}$ 7.4). Inset: redox difference spectrum of a membrane preparation at $5 \mathrm{mg}$ protein $\mathrm{ml}^{-1}$ in $5 \%$ Triton X100 and 50 mM sodium phosphate (pH 7.4). (b) Difference spectrum of the CO-bound reduced minus the reduced form of the purified cytochrome $a a_{3}$. The content was the same as for (a). 
Table 1. Purification of $a a_{3}$-type cytochrome $c$ oxidase

\begin{tabular}{|c|c|c|c|c|c|c|}
\hline \multirow[t]{2}{*}{ Purification steps } & \multirow{2}{*}{$\begin{array}{l}\text { Total protein } \\
\qquad(\mathbf{m g})\end{array}$} & \multicolumn{2}{|c|}{ Cytochrome $a_{3}$} & \multicolumn{3}{|c|}{ TMPD oxidase activity } \\
\hline & & $\begin{array}{c}\text { Total } \\
(\mathbf{n m o l})\end{array}$ & $\begin{array}{c}\text { Specific } \\
\left(\text { nmol mg }^{-1}\right)\end{array}$ & $\begin{array}{l}\text { Total } \\
\text { (units) }\end{array}$ & $\begin{array}{c}\text { Specific } \\
\left(\text { units } \mathrm{mg}^{-1}\right)\end{array}$ & $\begin{array}{l}\mathrm{TN}^{*} \\
\left(\mathrm{~s}^{-1}\right)\end{array}$ \\
\hline Membranes & 662 & $41 \cdot 0$ & $0 \cdot 0619$ & $26 \cdot 7$ & $0 \cdot 0403$ & $10 \cdot 8$ \\
\hline Cholate-washed & 583 & $42 \cdot 7$ & $0 \cdot 0732$ & $19 \cdot 4$ & $0 \cdot 0333$ & $7 \cdot 51$ \\
\hline DG-extracted & $47 \cdot 8$ & $44 \cdot 2$ & $0 \cdot 925$ & $1 \cdot 82$ & $0 \cdot 0381$ & $0 \cdot 68$ \\
\hline DEAE-Toyopearl & $6 \cdot 19$ & $13 \cdot 2$ & $2 \cdot 13$ & $1 \cdot 51$ & $0 \cdot 244$ & $1 \cdot 91$ \\
\hline Purified $a a_{3}$ & $0 \cdot 341$ & $2 \cdot 76$ & $8 \cdot 09$ & $0 \cdot 101$ & $0 \cdot 296$ & $0 \cdot 61$ \\
\hline
\end{tabular}

* Moles TMPD oxidized per mole cytochrome $a a_{3}$ per second.

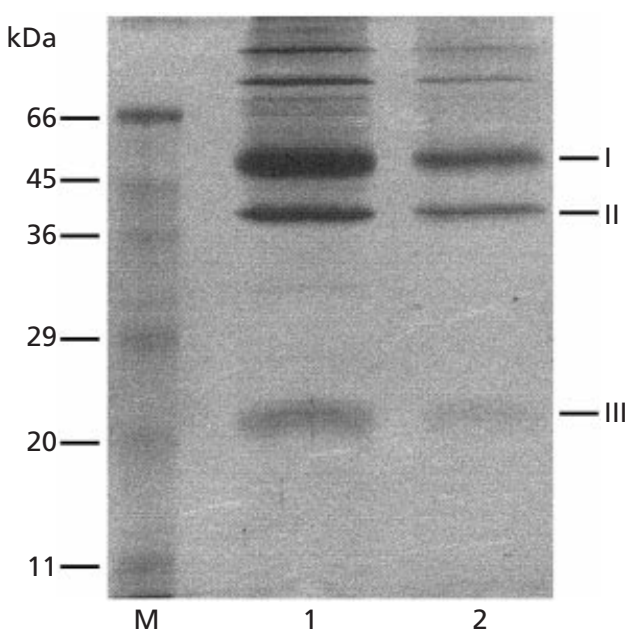

Fig. 2. SDS-PAGE analysis of cytochrome $a a_{3}$-type oxidase. Electrophoresis was performed using a $13.5 \%$ (w/v) acrylamide gel as described in Methods. Lane $M$, molecular mass standards; lane 2 , purified oxidase $(8 \mu \mathrm{g})$; lane 3 , the same sample $(3 \mu \mathrm{g})$. The roman numbers on the right indicate the positions of the three subunits.

\section{Chromophore and subunit composition}

The reduced form of the purified cytochrome showed the $\alpha$ - and $\gamma$-peaks at 600 and $442 \mathrm{~nm}$, respectively (Fig. 1a). The difference spectrum of the CO-reduced minus reduced forms demonstrates that the wavelength shift of the absorption peaks is due to haem A (Fig. 1b). These data clearly indicate that the cytochrome is of the $a a_{3}$ type. The haem A was extracted from the oxidase and analysed with reverse-phase chromatography and MALDI mass spectrometry. The haem was eluted from the reverse-phase column at a higher acetonitrile concentration than that of the control haem A extracted from thermophilic Bacillus cells (Sakamoto et al., 1997), suggesting that it is more hydrophobic than the usual type of haem A (data not shown). The molecular mass of the haem estimated by mass spectrometry was $920.09 \mathrm{Da}$, which is higher than that for normal haem A $(852.85 \mathrm{Da})$. The difference can be explained if it is assumed that the haem $\mathrm{A}$ of this oxidase has the geranylgeranyl side-chain $\left(\mathrm{C}_{20} \mathrm{H}_{26}{ }^{-}\right)$instead of the farnesyl group $\left(\mathrm{C}_{15} \mathrm{H}_{20^{-}}\right)$, as demonstrated for the haem As in archaeal quinol oxidase (Lübben \& Morand, 1994). Haem B extracted from the membranes of $C$. glutamicum showed a molecular mass of $616 \cdot 20 \mathrm{Da}$, which indicates that it is protohaem IX, the usual type of haem B (mol. mass 616.50 Da). SDS-PAGE analysis indicated that the final sample contained three main polypeptides, although the third band was relatively faint and was clearly visible only when the sample was overloaded (Fig. 2). The molecular masses estimated by using Ferguson plots were $64.3,40.5$ and $21.0 \mathrm{kDa}$, respectively. The molecular mass of the whole enzyme estimated from gel filtration was $160 \mathrm{kDa}$, which is compatible with the assumption that the enzyme is a heterotrimer bound by detergent micelles. The Nterminal sequence of subunit II was determined to be XEVAPPGGVLGDFLRMGWPDGI- by automated Edman degradation, whereas no appreciable amounts of PTH-amino acids were obtained from subunit I or subunit III.

\section{Genes for the three subunits}

The $c t a C$ gene for subunit II was isolated by using a probe prepared on the basis of the N-terminal peptide sequence of the subunit (Fig. 3a). The ctaE gene for subunit III was 1031 bp downstream of $c t a C$, whereas the gene for subunit I was not found in the vicinity. Therefore a new set of PCR primers was designed on the basis of highly conserved sequences in subunit I of the haem-copper oxidase superfamily. Thus, the whole $c t a D$ gene for subunit I was obtained (Fig. 3b). The total numbers of amino acid residues deduced from the genes are 584, 359 and 205, and the molecular masses are 65032,39518 and $22442 \mathrm{Da}$, respectively. The molecular masses estimated by MALDI mass spectrometry were $64955 \cdot 8 \pm 164 \cdot 1, \quad 37314 \cdot 7 \pm 83 \cdot 2$ and $22400 \cdot 7 \pm$ $27 \cdot 9 \mathrm{Da}$ (mean \pm sem, $n=6$ ), respectively. A comparison of these values indicated that subunit II, but not subunit I or subunit III, was significantly modified after translation (see below). The haem-copper oxidase family can be classified into the following three subgroups on the basis of the subunit composition and the primary structure: the SoxM group includes mito- 


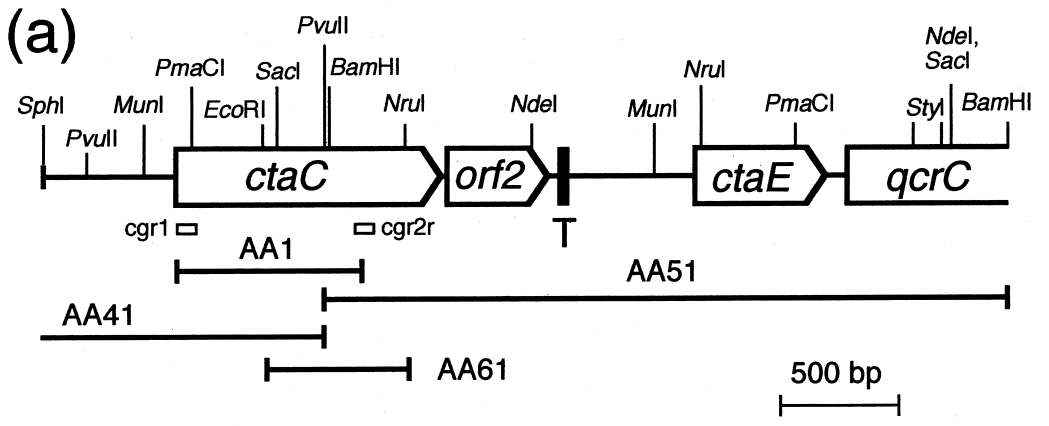

(b)

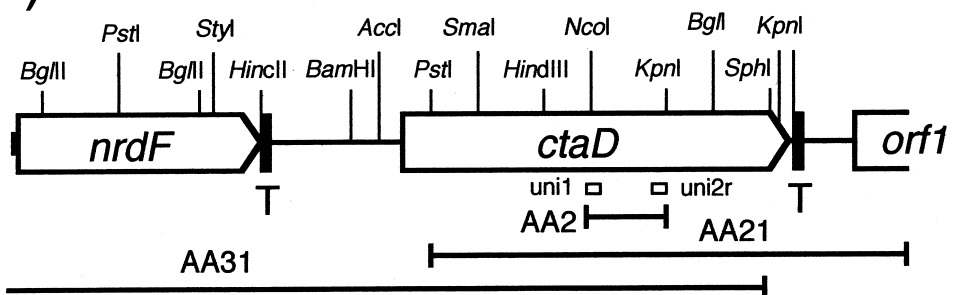

Fig. 3. Physical map of the genes for the three subunits of cytochrome $a_{3}$-type oxidase. Genes are indicated by open arrows. Solid rectangles ( $\mathrm{T})$, putative terminators with a palindromic sequence; open rectangles (cgr1, cgr2r, uni1, uni2r), PCR primers. PCR products (AA1, AA2) were used as probes to obtain the other clones (AA41, AA51, AA61, AA21, AA31).

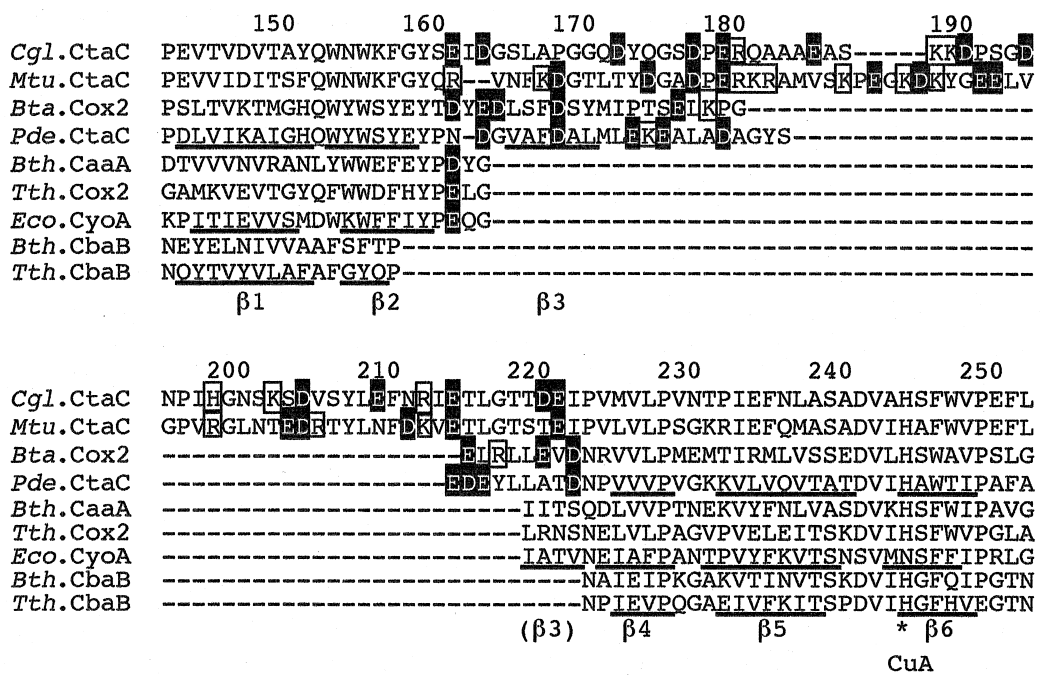

Fig. 4. Alignment of subunit II of several haem-copper oxidases. CtaC of C. glutamicum (Cgl.) was compared with eight counterparts by using CLUSTAL W (Thompson et al., 1994) followed by manual ajustment. The DDBJ/EMBL/GenBank accession numbers are as follows: $M$. tuberculosis (Mtu) $\mathrm{CtaC}$, Z70283; bovine cardiac (Bta), P00404; $P$. denitrificans (Pde) CtaC, P08306; B. thermodenitrificans (Bth) CaaA, D70843; $T$. thermophilus (Tth) CoxB, M59180; E. coli (Eco) CyoA, J05492; Bth CbaB, AB008757; $T$ th $\mathrm{CbaB}$, L09121. Solid underlines, $\beta$-strands identified in the crystal structures; open boxes, basic residues between $\beta 2$ and $\beta 4$ strands; solid boxes, acidic residues in the same regions.

chondrial oxidases, the SoxB group includes some oxidases from extremophiles, and the FixN group consists of cytochrome $c b b_{3}$ from microaerobic and aerobic proteobacteria (Castresana \& Saraste, 1995). Sequence comparison shows that the new oxidase belongs to the SoxM-type subfamily and is most similar to oxidases in other high-G + C Gram-positive bacteria, such as M. tuberculosis (Cole et al., 1998).

\section{Structural features of subunit II}

Comparison of the subunit II sequence obtained by Edman degradation (see above) with that deduced from the nucleotide sequence indicates that the $\mathrm{N}$-terminal signal peptide of the subunit is post-translationally cleaved between Gly28 and Cys29. The PTH-derivative of the first residue was not detected, while those of the following residues were clearly identified, suggesting that the Cys residue is modified but not $\mathrm{N}$-acetylated.
The cleaved site, -M-A-G-C-, fits the signal-sequence motif of lipoproteins, -L/M-A/S-G-C-, and is similar to those of the subunits II of other oxidases (Ishizuka et al., 1990; Quirk et al., 1993; Ma et al., 1997; Bengtsson et al., 1999). It was empirically demonstrated that the thiol group is diacylglycerated in the $\mathrm{Caa}_{3}$-type cytochrome $c$ oxidase from $B$. subtilis and the $b o_{3}$-type quinol oxidase from Escherichia coli. If it is assumed that the $\mathrm{N}$ terminal 28 residues of C. glutamicum subunit II are cleaved off and that the new N-terminal cysteine residue is distearoylglycerated, the calculated molecular mass is $37275 \mathrm{Da}$, which fits reasonably with the value estimated by MALDI mass spectrometry (see above). The atomic structures of the whole enzyme have been solved for cytochromes $a a_{3}$ of Paracoccus denitrificans (Iwata et al., 1995) and of bovine mitochondria (Tsukihara et al., 1996), cytochrome bo of E. coli (Abramson et al., 2000) and cytochrome $b a_{3}$ of Thermus thermophilus (Soulimane et al., 2000). The C-terminal extrinsic 


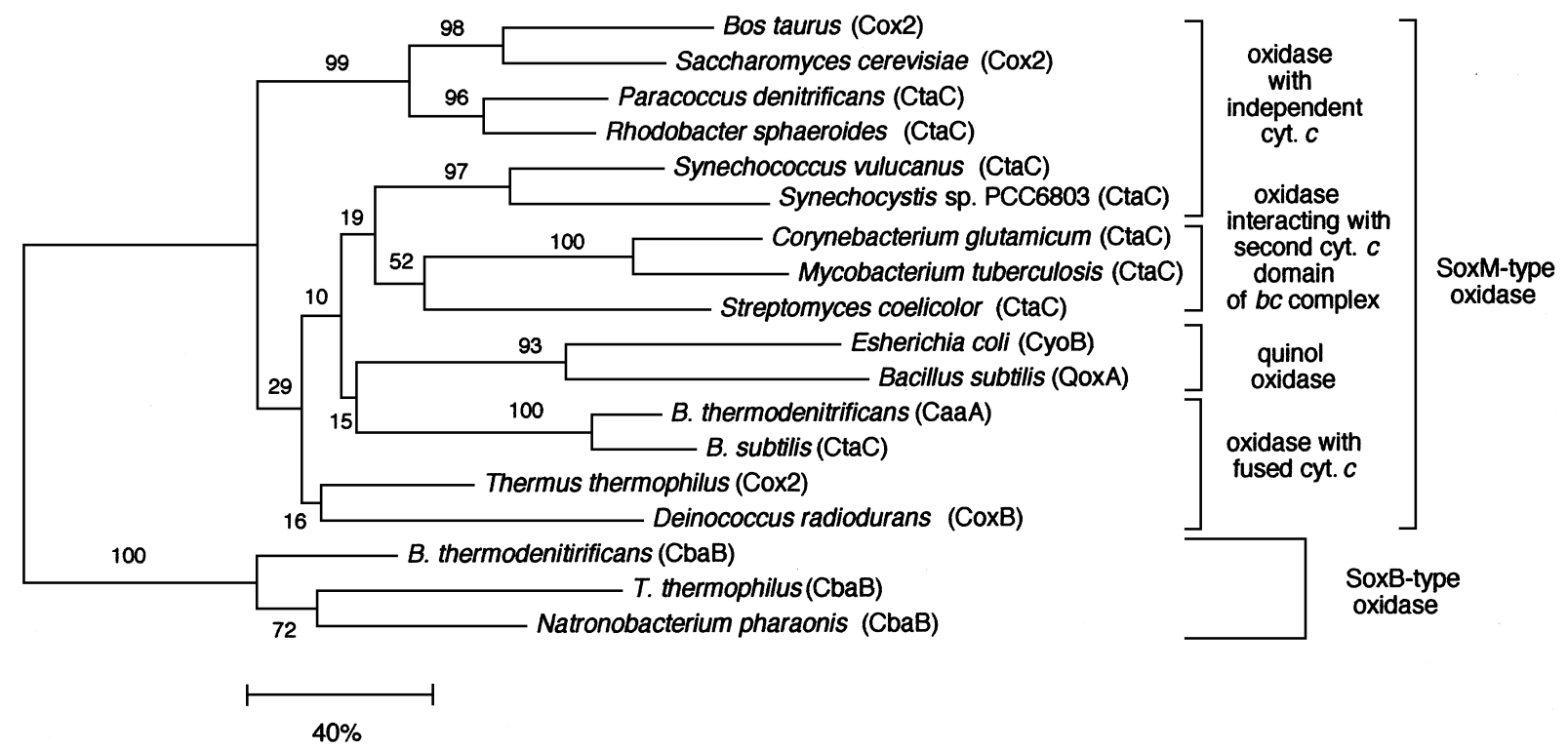

Fig. 5. Phylogenetic tree for subunit II of haem-copper oxidases. The tree was constructed on the basis of sequences between the transmembrane helix II and the 10th $\beta$-strand $(\beta 10)$ in the extrinsic domain of the subunit with CLustaL w, as described for Fig. 4. Additional sequence data were obtained from the DDBJ/EMBL/GenBank databases using the following accession numbers: Saccharomyces cerevisiae Cox2, V00685; Rhodobacter sphaeroides CtaC, M57680; Synechococcus vulcanus CtaC, P98054; Synechocystis sp. PCC6803 CtaC, D90905; B. subtilis CtaC, X54140; Streptomyces coelicolor Cox2, AL049497; Deinococcus radiodurans CoxB, AE002091; Natronobacterium pharaonis CbaB, Y10500. The numerals represent bootstrap confidence levels from 1000 bootstrap samples for the groupings. The scale bar represents a distance of $40 \%$.

domain of subunit II of these oxidases contains $10 \beta$ strands. Cytochrome $a a_{3}$ from C. glutamicum contains the $\mathrm{Cu}_{\mathrm{A}}$-binding motif $\left(\mathrm{HX}_{\mathrm{n}} \mathrm{CXEXCGX}_{2} \mathrm{HX}_{2} \mathrm{M}\right)$ in the same domain as the other SoxM- and SoxB-type cytochrome $c$ oxidases.

The most distinguishable structural feature is the extra cluster of charged amino acid residues between the $\beta 2$ and $\beta 4$ strands (Fig. 4). The length of this region varies among subgroups of the haem-copper oxidases. The first group consists of SoxB-type cytochrome $c$ oxidases, which have the shortest $\beta 2-\beta 4$ spans. The second group includes the $\mathrm{caa}_{3}$-type cytochrome $c$ oxidases and proteobacterial ubiquinol oxidases, in which this region is about 10 residues longer than that in the SoxB-type group. The third group is the largest, including all of the $a a_{3}$-type cytochrome $c$ oxidases from mitochondria and proteobacteria. These contain $\beta 2-\beta 4$ regions, rich in acidic residues, approximately 20 residues longer than those in the second group. Finally, as shown in this study, C. glutamicum $a a_{3}$-type oxidase, together with homologues from other high-G + C Gram-positive bacteria, contains the longest $\beta 2-\beta 4$ span (being about 30 residues longer than that in the third group), rich in both acidic and basic amino acids. The last three groups are all SoxM-type oxidases (Fig. 5).

\section{DISCUSSION}

C. glutamicum cytochrome $a a_{3}$ is a cytochrome $c$ oxidase, as indicated by its enzymic activity and the presence of the $\mathrm{Cu}_{\mathrm{A}}$-binding motif in subunit II (Fig. 4).
In spite of these clear indications, C. glutamicum cells do not contain small cytochrome $c$ which could serve as the intrinsic substrate. The only $c$-type cytochrome identified in this organism is the cytochrome $c c$ subunit of the $b c$ complex encoded by the $q c r C A B$ operon (Sone et al., 2001). The presence of a homologous gene and the absence of a gene for small cytochrome $c$ are confirmed in the whole genome of $M$. tuberculosis, a high-G $+\mathrm{C}$ Gram-positive bacterium related to C. glutamicum (Cole et al., 1998). Cytochrome $c c$ contains two type-I cytochrome $c$ domains. These findings suggest that one of the two domains plays a role equivalent to that of the cytochrome $c_{1}$ of the $b c_{1}$ complex, and the other a role comparable to that of small cytochrome $c$. In other words, the cytochrome $c c$-containing $b c$ complex might interact with the $a a_{3}$ oxidase in the absence of an electron carrier. In this context, one likely reason for the decline in TMPD oxidase activity upon solubilization (Table 1 ) is that the $b c$ complex and the $a a_{3}$ oxidase are associated in the intact membrane and dissociated upon solubilization, since TMPD is a more effective donor when cytochrome $c$ is bound to subunit II.

Genes for di-haem $\mathrm{C}$ proteins in $b c$ complexes are also found in the genomes of the $\varepsilon$-proteobacteria, such as Helicobacter pylori (Tomb et al., 1997), and in the photoautotrophic low-G + C Gram-positive Heliobacillus mobilis (Xiong et al., 1998). However, the only respiratory oxidase in the former organism is cytochrome $c b b_{3}$ (lacking a subunit-II homologue), and the $b c$ complex in the latter bacterium is encoded in a major photosynthesis gene cluster. The high-G + C Gram- 
positive bacteria have both a cytochrome $c c$-containing $b c$ complex and a subunit-II-containing terminal oxidase (Figs 4 and 5). The subunit II of these oxidases commonly contains an extra charged amino acid cluster in its cytochrome $c$-binding domain. These findings suggest that the inserted cluster may play a crucial role in the direct interaction and/or electron transfer between the $b c$ complex and the terminal oxidase in the new type of respiratory chain.

\section{ACKNOWLEDGEMENTS}

We would like to thank Drs P. H. Tsatsos and R. B. Gennis of Illinois University for their kind advice on the mass spectrometry of hydrophobic proteins. This study was supported by a grant-in-aid for Scientific Research (C) (10680617) and a grant on Priority Areas (08249233) from the Ministry of Education, Science, Sports, and Culture of Japan.

\section{REFERENCES}

Abramson, J., Riistama, S., Larsson, G., Jasaitis, A., Svensson-Ek, M., Laakkonen, L., Puustinen, A., Iwata, S. \& Wikström, M. (2000). The structure of the ubiquinol oxidase from Escherichia coli and its ubiquinone binding site. Nat Struct Biol 7, 910-917.

Bengtsson, J., Thalsma, H., Rivolta, C. \& Hederstedt, L. (1999). Subunit II of Bacillus subtilis cytochrome $c$ oxidase is a lipoprotein. J Bacteriol 181, 685-688.

Castresana, J. \& Saraste, M. (1995). Evolution of energetic metabolism: the respiration-early hypothesis. Trends Biochem Sci 20, 443-448.

Cole, S. T., Brosch, R., Parkhill, J. \& 39 other authors (1998). Deciphering the biology of Mycobacterium tuberculosis from the complete genome sequence. Nature 393, 537-544.

Ghaim, J. B., Tsatsos, P. H., Katsonouri, A., Mitchell, D. M., Salcedo-Hernandez, R. \& Gennis, R. B. (1997). Matrix-assisted laser desorption ionization mass spectrometry of membrane proteins: demonstration of a simple method to determine subunit molecular weights of hydrophobic subunits. Biochim Biophys Acta 1330, 113-120.

Ishizuka, M., Machida, K., Shimada, S., Mogi, A., Tsuchiya, T., Ohmori, T., Souma, Y., Gonda, M. \& Sone, N. (1990). Nucleotide sequences of the genes coding for four subunits of cytochrome $c$ oxidase from the thermophilic bacterium, PS3. J Biochem 108, 866-873.

Iwata, S., Ostermeier, C., Ludwig, B. \& Michel, H. (1995). Structure at $2 \cdot 8 \AA$ resolution of cytochrome $c$ oxidase from Paracoccus denitrificans. Nature 376, 660-669.

Kusumoto, K., Sakiyama, M., Sakamoto, J., Noguchi, S. \& Sone, N. (2000). Menaquinol oxidase activity and primary structure of cytochrome $b d$ from the amino-acid fermenting bacterium Corynebacterium glutamicum. Arch Microbiol 173, 390-397.

Lübben, M. \& Morand, K. (1994). Novel prenylated hemes as cofactors of cytochrome oxidases. Archaea have modified hemes A and O. J Biol Chem 269, 21473-21479.
Ma, J., Katsonouri, A. \& Gennis, R. B. (1997). Subunit II of the cytochrome $b_{3}$ ubiquinol oxidase from Escherichia coli is a lipoprotein. Biochemistry 36, 11298-11303.

Noguchi, S., Yamazaki, T., Yaginuma, A., Sakamoto, J. \& Sone, N. (1994). Overexpression of membrane-bound cytochrome $c$-551 from thermophilic Bacillus PS3 in Bacillus stearothermophilus K1041. Biochim Biophys Acta 1188, 302-310.

Quirk, P. G., Hicks, D. B. \& Krulwich, T. A. (1993). Cloning of the cta operon from alkaliphilic Bacillus firmus OF4 and characterization of the $\mathrm{pH}$-regulated cytochrome $\mathrm{caa}_{3}$ oxidase it encodes. J Biol Chem 268, 678-685.

Sakamoto, J., Matsumoto, A., Oobuchi, K. \& Sone, N. (1996). Cytochrome $b d$-type quinol oxidase in a mutant of Bacillus stearothermophilus deficient in $\mathrm{caa}_{3}$-type cytochrome $c$ oxidase. FEMS Microbiol Lett 143, 151-158.

Sakamoto, J., Handa, Y. \& Sone, N. (1997). A novel cytochrome $b(o / a)_{3}$-type oxidase from Bacillus stearothermophilus catalyzes cytochrome $c-551$ oxidation. J Biochem 122, 764-771.

Sakamoto, J., Koga, E., Mizuta, T., Sato, C., Noguchi, S. \& Sone, N. (1999). Gene structure and quinol oxidase activity of a cytochrome $b d$-type oxidase from Bacillus stearothermophilus. Biochim Biophys Acta 1411, 147-158.

Sone, N. \& Yanagita, Y. (1982). A cytochrome $a a_{3}$-type terminal oxidase of a thermophilic bacterium: purification, properties and proton pumping. Biochim Biophys Acta 682, 216-226.

Sone, N., Sekimachi, M. \& Kutoh, E. (1987). Identification and properties of a quinol oxidase super-complex composed of a $b c_{1}$ complex and cytochrome oxidase in the thermophilic bacterium, PS3. J Biol Chem 262, 15386-15391.

Sone, N., Nagata, K., Kojima, H., Tajima, J., Kodera, Y., Kanamaru, T., Noguchi, S. \& Sakamoto, J. (2001). A novel hydrophobic diheme $c$-type cytochrome. Purification from Corynebacterium glutamicum and analysis of the QcrCBA operon encoding three subunit proteins of a putative cytochrome reductase complex. Biochim Biophys Acta 1503, 279-290.

Soulimane, T., Buse, G., Bourenkov, G.P., Bartunik, H. D., Huber, R. \& Than, M. E. (2000). Structure and mechanism of the aberrant $b a_{3}$-cytochrome $c$ oxidase from Thermus thermophilus. EMBO J 19, 1766-1776.

Thompson, J. D., Higgins, D. G. \& Gibson, T. J. (1994). CLUSTAL w : improving the sensitivity of progressive multiple sequence alignment through sequence weighting, position specific gap penalties and weight matrix choice. Nucleic Acids Res 22, 4673-4680.

Tomb, J.-F., White, O., Kerlavage, A. R. \& 39 other authors (1997). The complete genome sequence of the gastric pathogen Helicobacter pylori. Nature 388, 539-547.

Tsukihara, T., Aoyama, H., Yamashita, E., Tomizaki, T., Yamaguchi, H., Shinzawa-Itoh, K., Nakashima, R., Yaono, R. \& Yoshikawa, S. (1996). The whole structure of the 13 -subunit oxidized cytochrome $c$ oxidase at 2·8 A. Science 272, 1136-114.

von Wachenfeldt, C. \& Hederstedt, L. (1993). Physico-chemical characterisation of membrane-bound and water-soluble forms of Bacillus subtilis cytochrome c-550. Eur J Biochem 212, 499-509.

Xiong, J., Inoue, K. \& Bauer, C. E. (1998). Tracking molecular evolution of photosynthesis by characterization of a major photosynthesis gene cluster from Heliobacillus mobilis. Proc Natl Acad Sci U S A 95, 14851-14856.

Received 20 March 2001; revised 19 June 2001; accepted 28 June 2001. 